\title{
Selective Voltammetric Detection of Chlorophylls Using a Semi- circular Potential Wave
}

\author{
Yuanzhe Wang, Lifu Chen, Richard G Compton* \\ Department of Chemistry, Physical and Theoretical Chemistry Laboratory, Oxford University, \\ South Parks Road, Oxford OX1 3QZ, UK
}

*Corresponding author

Email: richard.compton@chem.ox.ac.uk

Phone: +44 (0) $1865275957 \quad$ Fax: +44 (0) 1865275410

Email addresses of co-authors:

yuanzhe.wang@wadham.ox.ac.uk

lifu.chen@chem.ox.ac.uk

To be submitted to:

Food Chemistry 
2 A simple electrochemical method employing a novel semi-circular potential sweep voltammetry on a glassy carbon (GC) electrode was developed to distinguish and quantify two main chlorophyll components

4 (chlorophyll $a$ and $b$ ) present in their mixtures. The semi-circular potential sweep generates large, transient 5 scan rates, enabling the selective detection of species with closely similar oxidative potentials. The proposed 6 method shows good applicability in mixtures of chlorophyll a (Chl a) and chlorophyll b (Chl b) with concentrations ranging from 46.2 to $110.8 \mu \mathrm{M}$ and 46.2 to $92.4 \mu \mathrm{M}$ respectively, which were prepared to

8 mimic varying compositions of chlorophyll $\mathrm{a}$ and $\mathrm{b}$ in nature for the application in food quality control. The 9 method was successfully applied to real sample of spinach.

10

11

12

13

14

15

16

17

18

19

20

21

\section{Keywords:}

Chlorophyll

Semi-circular potential sweep voltammetry

\section{Detection in Mixtures}

\section{Introduction}

In electroanalysis, cyclic voltammetry $(\mathrm{CV})$ is a widely used technique, in particular, for initial analysis of new redox systems, providing abundant information such as rate constants, formal potentials, electron transfer coefficients to study the kinetics and thermodynamics of electrochemical reactions (Bard, Faulkner,

$$
E(t)= \pm v t+E(t=0)
$$

Zoski, \& Leddy, 2001). It employs a linear potential waveform (Compton \& Banks, 2018):

where the \pm sign indicates the oxidation or reduction of the studied reaction and $v$ is the scan rate that remains constant. However, an alternative method has been proposed recently, employing a semi-circular potential wave as follows (Y. Uchida, Katelhon, \& Compton, 2018a, 2018b):

$$
E(t)= \pm A_{0} \sqrt{\left|1-\left[2\left(\frac{t}{t_{\max }}-c\right)\right]^{2}\right|}+E_{\text {centre }}
$$




$$
E_{\text {centre }}=\frac{E_{f}-E_{i}}{2}
$$

where $A_{0}$ is the amplitude of the potential wave, $t$ is the time and $t_{\max }$ is the duration of a single scan between the two potential limits. $\mathrm{c}=0$ for $t \leq t_{\max } / 2, \mathrm{c}=1$ for $t_{\max } / 2<t<t_{\max }$ and $E_{\text {centre }}$ is the midpoint of the applied potential window, which is experimentally defined relative to the reference electrode with the start potential $E_{i}$ and the vertex potential $E_{f}$. The main features of semi-circular potential wave in contrast to conventional linear wave are that it generates an instantaneous infinite scan rate at the midpoint of the potential window and relatively slower scan rates in other regions. The current response, which is dependent on the scan rate, can thus be selectively amplified at a desired potential while compressed at others. This novel method giving significant current amplification was validated by Uchida et al. via simulation (Y. Uchida, Katelhon, \& Compton, 2019), where its use for determining standard electrochemical rate constants, $k_{0}$, with one magnitude greater accuracy than via conventional $\mathrm{CV}$ was also suggested. The experimental verification of semi-circular potential sweep voltammetry was performed on the well-known redox couple $\mathrm{Ru}\left(\mathrm{NH}_{3}\right)^{3+/ 2+}$, showing good agreement with theory and a potential use in determining the formal potential (Amin, Uchida, Katelhon, \& Compton, 2019).

The use of semi-circular potential sweep voltammetry for electroanalytical applications is just beginning to be investigated computationally and experimentally. The main advantage of applying a semi-circular potential wave is its ability to generate the markedly increased current response and thus improve the detection sensitivity. This was demonstrated by Uchida et al. in a theoretical study employing semi-circular potential sweep in stripping voltammetry designed for the adsorbed species (Y Uchida, Kätelhön, \& Compton, 2019). Further, the use of semi-circular potential sweep voltammetry in experiments for a diffusion-controlled electrochemical process to obtain amplified signals facilitating simple data analysis was reported in our recent work on quantification of piperine in black pepper (Wang, Chen, Chaisiwamongkhol, \& Compton, 2019).

In order to further appreciate semi-circular potential sweep voltammetry and in particular, develop it into a powerful tool for electroanalytical applications, we herein apply the semi-circular potential sweep voltammetry to the analysis of a mixture of two species. As predicted by Uchida et al on the basis of computational simulation (Y. Uchida et al., 2018b), semi-circular voltammetry is advantageous over conventional $\mathrm{CV}$ in distinguishing two individual species from a mixture, in particular, when they have 
closely similar peak potentials in classical CV. To demonstrate this experimentally, chlorophyll a (Chl a) and chlorophyll b (Chl b), and their closely similar redox potentials (Goedheer, Dehaas, \& Schuller, 1958; Kobayashi et al., 2007; Nonomura, Igarashi, Yoshioka, \& Inoue, 1997).

The chlorophylls are a group of tetrapyrrolic pigments involved in photosynthesis in higher plants, algae, and some species of bacteria. Chl a and $\mathrm{Chl} \mathrm{b}$ are two major light-adsorbing pigments (Scheer, 1991), playing pivotal roles in the electron transfer that occurs at the reaction centres of both photosystem I and photosystem II . They are very similar in structure and found to coexist in many oxygenic photosynthetic organisms (Scheer, 1991). Both of them possess the porphyrin ring coordinating to a central magnesium ion while $\mathrm{Chl}$ a distinguishes from $\mathrm{Chl} b$ by its 7-methyl-substitutent rather than 7-formyl functional group (Figure $1(\mathrm{~A})(\mathrm{B}))$. The chlorophylls were reported to show prooxidant activities under light, transferring the energy absorbed from light to the present triplet oxygen to form highly reactive singlet oxygen but act as antioxidants at dark conditions owing to the structure of their porphyrin rings. Chl a was found to possess a higher prooxidant activity than $\mathrm{Chl} b$ whereas $\mathrm{Chl} b$ is a stronger antioxidant (Choe \& Min, 2006).

Due to their important roles in photosynthetic process and abundant presences in nature, determinations of chlorophylls are required for both mechanism investigations and industrial / agricultural analysis including quality control of crops (Zhang et al., 2016) and food products (Schoefs, 2003), as well as measurements of phytoplankton (Boyer, Kelble, Ortner, \& Rudnick, 2009) biomasses for applications in water quality monitoring and environmental pollution assessment. In particular, for many types of edible oil products, for example and notably, extra virgin olive oil, chlorophylls and their degradation products such as pheophytins and pyropheophytins can serve as indicators of the product storage stability due to their prooxidant or antioxidant behaviours, which have clear effects on the photosensitized oxidation or autoxidation of the product (Choe \& Min, 2006). Extra virgin olive oil has generally been suggested as needing to be stored in the dark to maintain its overall oxidative stability and nutritional value, preventing the degradation of some minority compounds including chlorophyll (present mainly as pheophytin a in this product) which reduces the autoxidation of the oil in the dark (Cecchi, Passamonti, \& Cecchi, 2010; Silva, Anjos, Cavalcanti, \& Celeghini, 2015). Light accelerates the oil oxidation by triggering the reaction of singlet oxygen via photosensitized oxidation. Packaging technologies such as applying oxygen scavengers (Cecchi, Passamonti, \& Cecchi, 2010) and light filtering packaging materials (Trypidis et al., 2019) can help better maintain the quality of oil under light, although they may become less effective when high concentrations of chlorophyll 
as prooxidant are present (Trypidis et al., 2019). Moreover, pyropheophytins have been reported to be very sensitive to temperature, another factor affecting the shelf-life of extra virgin olive oil, therefore these molecules can be used as a freshness parameter indicating exposure to temperature changes over $25^{\circ} \mathrm{C}$ (Conte et al., 2020).

Among a variety of techniques for chlorophyll identification and quantification, spectrophotometry (Ergun, Demirata, Gumus, \& Apak, 2004), UV-vis (Vernon \& Seely, 1966) and fluorescence (Maxwell \& Johnson, 2000) spectroscopy are most commonly used for routine detections, offering good specificity and sensitivity based on their characteristic light-absorbing/emitting properties. Nonetheless, electrochemical methods are potentially a facile and accurate replacement of the spectroscopic methods and have also been studied extensively on gold (Khanova \& Tarasevich, 1987), mercury (Agostiano, Cosma, \& Dellamonica, 1990), platinum (Suponeva, Kazakova, \& Kisselev, 1989), $\mathrm{SnO}_{2}$ (Yang, Zhou, Han, \& Jiang, 1994) electrodes as well as carbon electrodes (Nonomura et al., 1997; cPemberton, Amine, \& Hart, 2004; Suponeva, Hotchandani, Arbour, \& Kisselev, 1996) using cyclic voltammetry and more sensitive electroanalytical techniques including adsorptive stripping voltammetry (AdSV), differential pulse voltammetry (DPV) and square wave voltammetry (SWV). For the structurally similar $\mathrm{Chl}$ a and $\mathrm{Chl} \mathrm{b}$, the similar square wave voltammograms were found (Kobayashi et al., 2007) and close redox potential values of them were reported (Goedheer et al., 1958; Kobayashi et al., 2007) at platinum electrode in non-aqueous media. While most of the studies focus on merely the mechanistic interpretations of chlorophylls, Pemberton et al. reported the electro-oxidation behaviours of $\mathrm{Chl}$ a using screen-printed carbon electrode and developed an approach for its detection in cow faeces (Pemberton et al., 2004). However, the aforementioned electrochemical studies all focus on either the singular chlorophyll determination or simply the total chlorophyll $(a+b)$ mixture, Chl a and $\mathrm{Chl} \mathrm{b}$ have not been distinguished electrochemically in the mixture resulting from direct extraction from common green vegetables. Developing a simple, rapid and sensitive method to detect and distinguish the structurally similar $\mathrm{Chl}$ a and $\mathrm{Chl} b$ that possess different properties, like prooxidant/antioxidant capabilities, is crucial for performing quantitative analysis of each substance and accurately evaluating the qualities of mixtures in industry, which may also be meaningful when consider the detections of other similar compounds such as pheophytins and pyropheophytins. 
In this work, we present an electroanalytical method employing semi-circular potential sweep voltammetry

to distinguish and quantify two structurally similar compounds in a mixture. First, the electrochemical behaviour of $\mathrm{Chl}$ a and $\mathrm{Chl} b$ are investigated using cyclic voltammetry on a GC electrode. The applicability of the developed method using semi-circular potential sweep voltammetry in detecting Chl a and Chl b individually in a 1:1 mixture is next demonstrated. Finally, its potential application in determining the chlorophyll content of a spinach sample is suggested.

\section{Experimental}

\subsection{Chemicals and Reagents}

Chlorophyll a and $\mathrm{b}$ were extracted and partially purified from fresh spinach leaves based on a previously published method (Iriyama \& Shiraki, 1979), followed by subsequent purification performed on a silica gel column chromatography using $60 \AA$ silica gel 40-63 $\mu$ m purchased from VWR. A detailed procedure of extraction and column chromatography purification is fully described in Section 1 of the Supporting Information. The spinach was purchased fresh from a local supermarket (Tesco, Oxford, UK). The products of $\mathrm{Chl} \mathrm{a}$ and $\mathrm{Chl} \mathrm{b}$ obtained from $100 \mathrm{~g}$ spinach were weighed as $22.3 \mathrm{mg}$ and $6.2 \mathrm{mg}$ and dissolved in acetone or diethyl ether for further measurements. Stock solutions in acetone were stored in the dark at $19{ }^{\circ} \mathrm{C}$. The purity and concentration of samples were routinely checked by UV-vis spectroscopy in ether solutions. All other chemicals were of analytical grade and were used received without any further purification. The chlorophyll solutions were prepared with acetone $(\geq 99.8 \%)$ and diethyl ether $(\geq 99.8 \%)$ purchased from Sigma-Aldrich. All solutions for electrochemical measurements were prepared with deionised water at a resistivity of $18.2 \mathrm{M} \Omega \mathrm{cm}$ at $298 \mathrm{~K}$ (Millipore, MA, USA). The phosphate-buffered saline (PBS, $1 \times, \mathrm{pH}=7.4$ ) was prepared using sodium chloride $(137 \mathrm{mM}, \geq 99.5 \%)$, potassium chloride $(2.7$ $\mathrm{mM}, \geq 99.0 \%)$, sodium phosphate dibasic $(10 \mathrm{mM}, \geq 99.0 \%)$, and potassium phosphate monobasic (1.8 $\mathrm{mM}$, $\geq 99.0 \%$ ), purchased from Sigma-Aldrich.

\subsection{Apparatus}



mm optical path. The absorbance was recorded from $800-300 \mathrm{~nm}$ and a baseline correction was conducted prior to all measurements.

All electrochemical experiments were conducted with a standard three-electrode system in a Faraday cage at $298 \mathrm{~K}$. The cyclic voltammetric measurements were performed using a $\mu$ Autolab II potentiostat (MetrohmAutolab BV, Netherlands). Semi-circular potential wave sweep voltammetry was carried out with a computer-controlled in-lab built potentiostat ensuring the low-noise measurements with signal sampled at a stream rate of $100 \mathrm{kHz}$ (Amin et al., 2019). The potentiostat was controlled by script written in Python 3.5 to generate required potential waveform. For the voltammetric measurements, a glassy carbon (GC) macroelectrode (diameter calibrated as $2.99 \mathrm{~mm}$ ) was used as the working electrode, a saturated calomel electrode (SCE, ALS distributed by BASi Inc., Japan.) as the reference electrode and a graphite rod as the counter electrode. The GC electrode was polished onto the soft lapping pads (Buehler, UK) with alumina (particles size of 1.0 and $0.3 \mu \mathrm{m}$, Buehler, IL, UK) before each voltammetric experiment, followed by sonication in water and drying with nitrogen.

\subsection{Analytical Procedure}

The purities of $\mathrm{Chl} a$ and $\mathrm{Chl} b$ fractions obtained from column chromatography were first examined in ether solutions using UV-vis spectroscopy. The spectral absorption properties (adsorption peak shapes, adsorption maxima and band ratios) shown on the UV-vis spectras (Figure S1) of Chl a and Chl b were compared with the values reported in literature (Section 2 in Supporting Information). Chl a and Chl b were next resolubilised in acetone and prepared as stocking solutions $(370 \mu \mathrm{M})$. The concentrations of $\mathrm{Chl}$ a and Chl b solutions in acetone were determined using UV-vis spectroscopy. The stock solutions were then diluted to the concentrations of $1.45-111 \mu \mathrm{M}$ as standard working solutions.

All experiments were conducted under dim light and solution was bubbled with $\mathrm{N}_{2}$ for 10 minutes to remove dissolved oxygen before each measurement. The chlorophyll standard mixture solutions are prepared by adding increasing concentrations of $\mathrm{Chl}$ a or $\mathrm{Chl} b$ from $9.24-64.6 \mu \mathrm{M}$ to a 1:1 mixture containing 46.2 $\mu \mathrm{M}$ Chl a and Chl b. For cyclic voltammetric and semi-circular potential sweep voltammetric experiments using the standard solutions, the GC electrode was immersed in the $\mathrm{Chl}$ a and / or $\mathrm{Chl} \mathrm{b}$ acetone solutions for 
157 one minute to allow the adsorption of chlorophyll onto the electrode surface. The electrode was then gently

158 rinsed with deionised water and transferred to the blank degassed PBS solution at $\mathrm{pH} 7.4$ for voltammetric 159 measurements.

160 For real sample analysis, the yielded crude product from the extraction of spinach without column 161 chromatographic purification was diluted with acetone until the voltammetric responses fell within the linear 162 detection range (dilution factor $=50$ ) and used for the initial cyclic voltammetric and semi-circular 163 voltammetric tests. The same electrode preparation procedure was used as above. The Chl a standard 164 solutions in the concentration range of $23.1-80.9 \mu \mathrm{M}$ were then added to the crude for quantification in real 165 samples using semi-circular potential sweep voltammetry.

\section{Results and Discussion}

167 In the following sections, first, the electrochemical behaviour of $\mathrm{Chl}$ a and $\mathrm{Chl} b$ separately adsorbed on a

168 GC electrode are studied and compared using CV. Next, semi-circular potential sweep voltammetry is 169 employed for selective detection of $\mathrm{Chl}$ a and $\mathrm{Chl} \mathrm{b}$ in a 1:1 mixture of them, as well as compared to the conventional CV method. The potential window is optimised to give the best resolution of chlorophyll peaks

171 in mixture detection and used for the standard additions analysis of $\mathrm{Chl}$ a and $\mathrm{Chl} \mathrm{b}$. Finally, standard 172 additions of $\mathrm{Chl}$ a to a real sample of spinach is conducted for application in food quality control. 
(A)

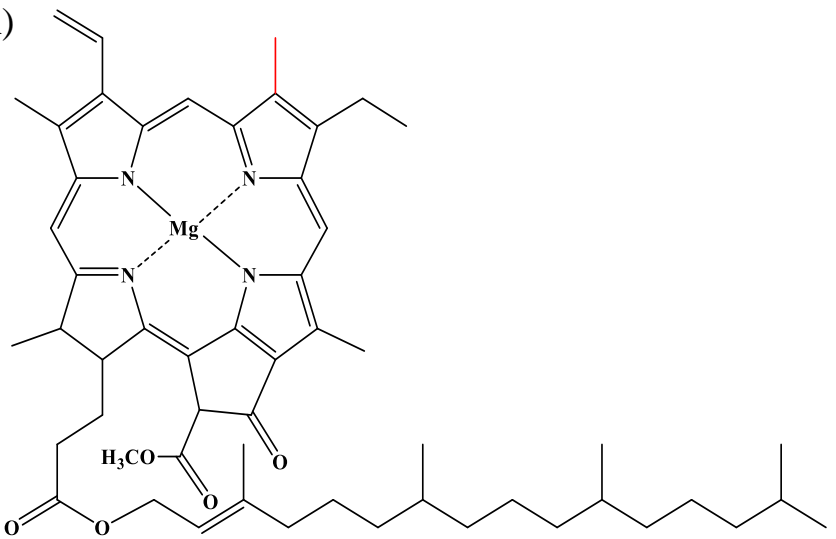

(B)

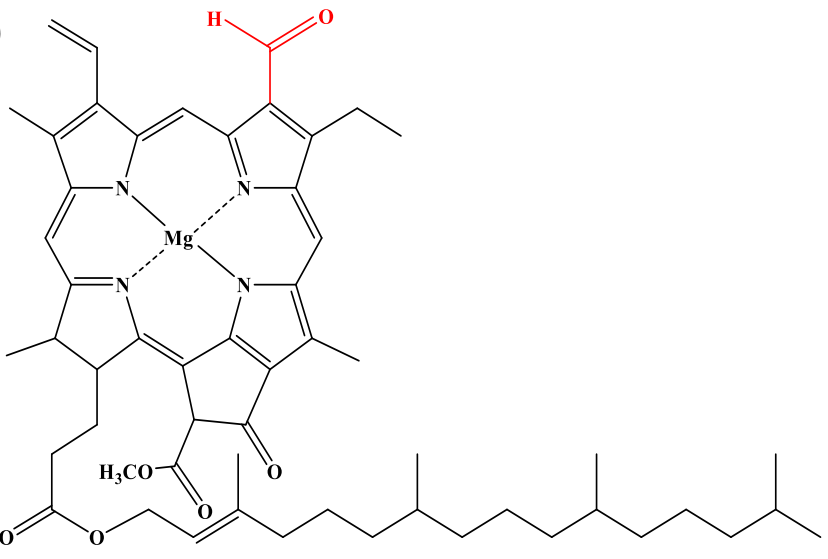

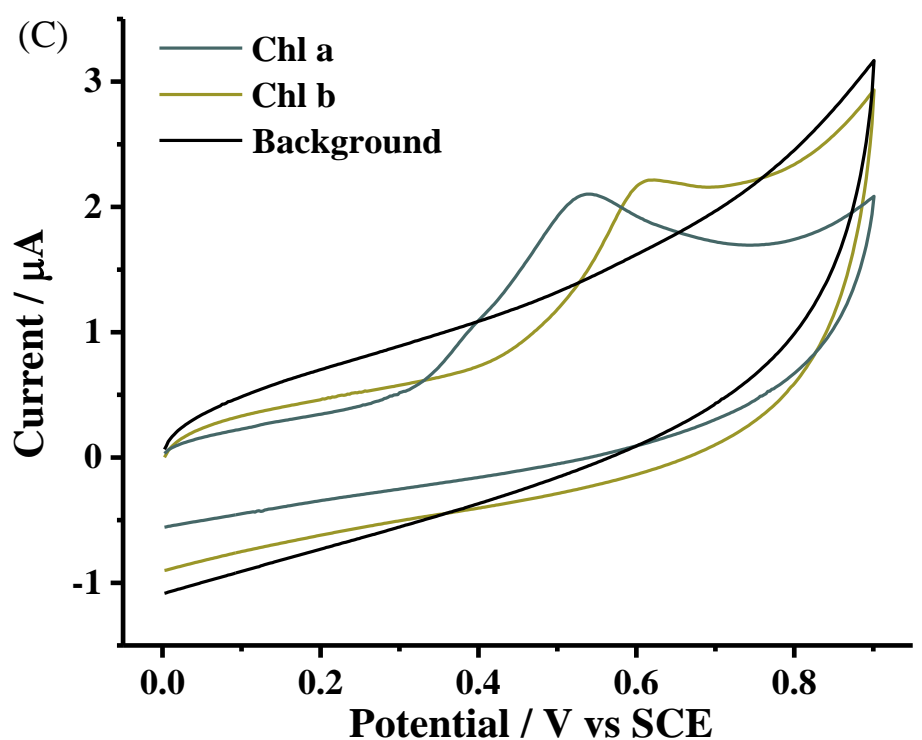

Figure 1. Chemical structures and electrochemical signals: Chemical structures of (A) chlorophyll a and (B) chlorophyll b. (C) Cyclic voltammetric responses of background, 23.1 $\mu \mathrm{M} \mathrm{Chl} \mathrm{a} \mathrm{and} \mathrm{Chl} \mathrm{b}$ at GC electrode measured in PBS under degassed condition. Scan rate $=100 \mathrm{mVs}^{-1}$

The voltammetric behaviour of $\mathrm{Chl}$ a and $\mathrm{Chl} b$ separately on a GC electrode were first investigated using conventional cyclic voltammetry. The GC electrode was immersed in $23.1 \mu \mathrm{M}$ of $\mathrm{Chl}$ a or $11.6 \mu \mathrm{M}$ of $\mathrm{Chl} \mathrm{b}$ solutions for one minute before being transferred to a degassed PBS solution. Cyclic voltammetric responses of $\mathrm{Chl}$ a and $\mathrm{Chl} \mathrm{b}$ were recorded at a scan rate of $100 \mathrm{mV} \mathrm{s}^{-1}$, showing an irreversible oxidation peak at $+0.54 \mathrm{~V}$ vs. SCE for Chl a and another irreversible oxidation peak at $+0.62 \mathrm{~V}$ vs. SCE for Chl $\mathrm{b}$ in the chosen potential window (Figure 1(C)). As can be seen, the voltammograms of the two chlorophylls appeared to be

closely similar at GC electrode, except that the oxidation of $\mathrm{Chl} b$ is shifted to a slightly more positive potential, which reflects the change of a $-\mathrm{CH}_{3}$ substituent group ( $\mathrm{Chl}$ a) to an electron withdrawing group - 
$\mathrm{CHO}(\mathrm{Chl} b)$ reducing the electron density of chlorophyll $\pi$-conjugated system (Falk \& Smith, 1975; Scheer, 1991).

To confirm the adsorption of $\mathrm{Chl}$ a and $\mathrm{Chl} \mathrm{b}$ onto GC electrode surface, the effects of scan rate on the oxidation peak currents were studied. Figure 2(A) and (B) depicts the cyclic voltammograms of Chl a and $\mathrm{Chl} \mathrm{b}$ recorded at the scan rates in the range of 25 to $400 \mathrm{mVs}^{-1}$. Linear relationships between peak currents and scan rates were found for both compounds from 25 to $400 \mathrm{mVs}^{-1}$ (Insets of Figure 2(A) and 2(B)), suggesting the observed oxidations of $\mathrm{Chl}$ a and $\mathrm{Chl} b$ are both surface bound processes.

\subsubsection{Adsorption on GC electrode}

Having identified the chlorophyll electrochemistry as from surface-confined species, the adsorption of the chlorophylls on GC electrode surface was next investigated. Cyclic voltammetry of Chl a at varying concentrations was performed with an immersion time of one minute, which was experimentally determined to be the minimum time required for the voltammetric peak areas to reach a plateau and so leading to a sensitive and reproducible detection of the chlorophylls (Section 3 in Supporting Information). The cyclic voltammetric responses of $\mathrm{Chl}$ a in the concentration range of $1.45-370 \mu \mathrm{M}$, at a scan rate of $100 \mathrm{mVs}^{-1}$ were

$$
\theta=\frac{K[C]}{1+K[C]}
$$

recorded in Figure 2(C), which was analysed with Langmuir isotherm according to the following equation:

where $\theta$ is the fractional occupancy of the adsorption sites, $K$ is the equilibrium constant for adsorption and $[C]$ is the concentration of Chl a. Eq. (4) can be rewritten as:

$$
\frac{1}{Q}=\left(\frac{1}{K Q_{\max }}\right)\left(\frac{1}{[C]}\right)+\frac{1}{Q_{\max }}
$$

where $Q$ is the voltammetrically measured charge transferred during oxidation of the species at the studied concentrations and $Q_{\max }$ is maximum charge transfer at saturation of the surface with $\mathrm{Chl}$ a. The Langmuir plot shown in Figure 2(D) exhibits a linearity $\left(1 / Q\left(\mu \mathrm{C}^{-1}\right)=(3.290 \pm 0.119) 1 / C\left(\mu \mathrm{M}^{-1}\right)+(0.237 \pm 0.0378)\right.$, $\mathrm{R}^{2}=0.996$ ), suggesting the $\mathrm{Chl}$ a adsorption is well-described by the Langmuir isotherm. The equilibrium constant $K$ and maximum charge transfer $Q_{\max }$ were calculated to be $0.072 \mu \mathrm{M}^{-1}$ and $4.2 \mu \mathrm{C}$, respectively. 

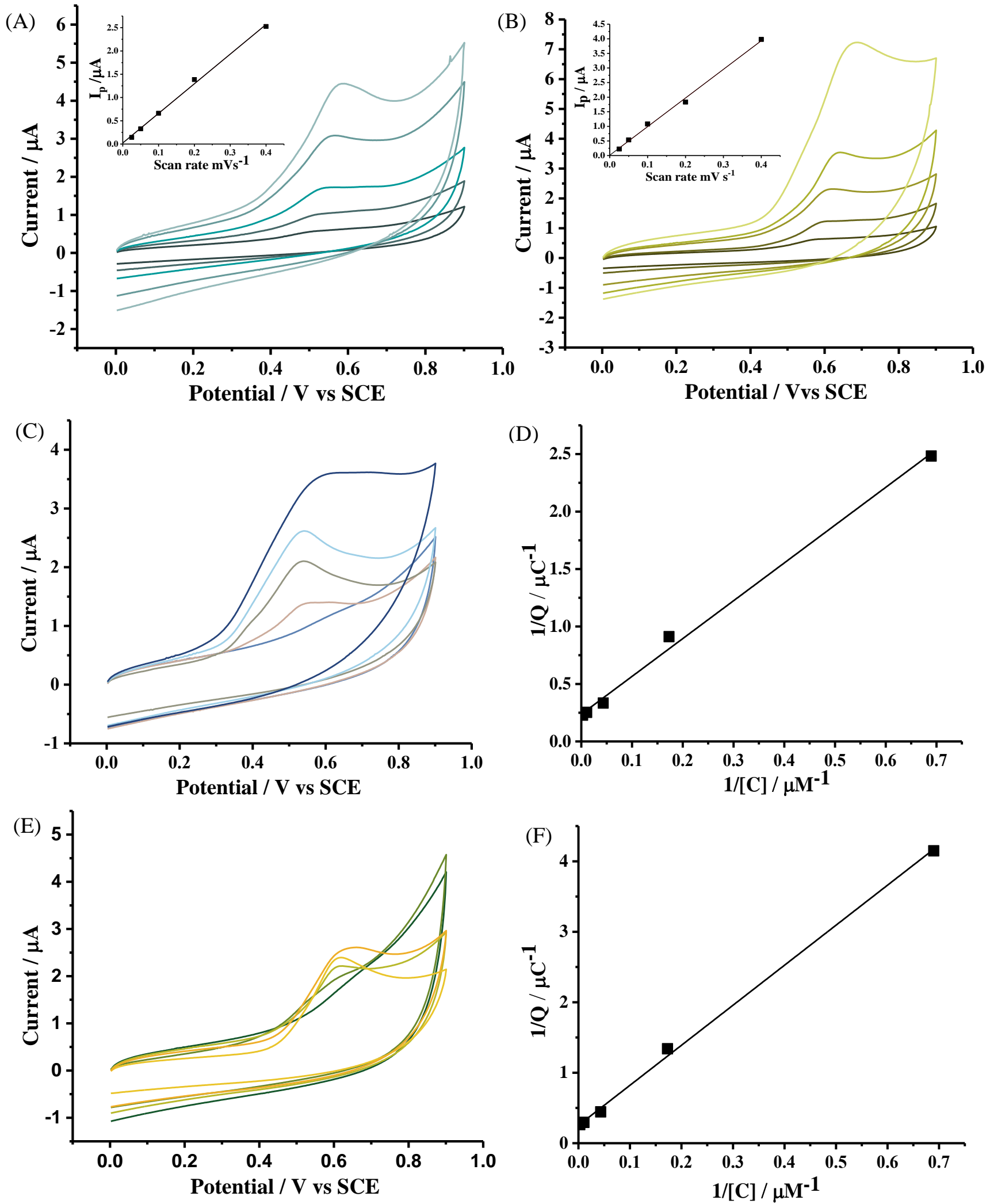

Figure 2. Electrochemical behaviours of chlorophylls: Cyclic voltammetric responses of (A) $11.6 \mu \mathrm{M}$ Chl a oxidation and (B) 23.1 $\mu \mathrm{M}$ Chl b at GC electrode in PBS at varying scan rates of $25 \mathrm{mvs}^{-1}, 50 \mathrm{mvs}^{-1}, 100 \mathrm{mvs}^{-1}, 150 \mathrm{mvs}^{-1}, 200 \mathrm{mvs}^{-1}, 400 \mathrm{mvs}^{-1}, \mathrm{under}^{-}$ degassed condition. Inset: plot of peak current versus scan rate; increasing concentrations from 1.45-370 $\mu \mathrm{M}$ of $(\mathrm{C}) \mathrm{Chl}$ a and $(\mathrm{E}) \mathrm{Chl}$ $\mathrm{b}$ at GC electrode in PBS. Langmuir plot of (D)1.45-370 $\mu \mathrm{M} \mathrm{Chl} \mathrm{a} \mathrm{using} \mathrm{peak} \mathrm{area} \mathrm{obtained} \mathrm{from} \mathrm{(C)} \mathrm{and} \mathrm{(F)} 1.45-370 \mu \mathrm{M} \mathrm{Chl} \mathrm{b}$ using peak area obtained from (D).

In order to estimate the approximate area of a Chl a molecule adsorbed on $\mathrm{GC}$, the theoretical areas of the

molecule in all three possible flat molecular orientations were calculated using the rectangular box model presented in Scheme 1. All side lengths were estimated by trigonometry for bond lengths, bond angles and 
van der Waals radii of the terminating atoms. The bond length, bond angles data were obtained from ChemDraw 16.0 software and the van der Waals radii of the terminating atoms values are those tabulated by Rowland (Batsanov, 2001). This method has been reported in several previous studies for other organic molecules (Chen, Tanner, Lin, \& Compton, 2018; Chen, Li, Tanner, \& Compton, 2017). Scheme 1 shows the flat view (A), edgewise view (B) and endwise view (C) of Chl a adsorption on GC electrode and the corresponding areas $A_{\mathrm{fl}}, A_{\mathrm{ed}}, A_{\mathrm{en}}$ can be estimated as $4.93,2.80,1.93 \times 10^{-14} \mathrm{~cm}^{2}$. The number of molecules adsorbed on electrode surface $\left(N_{\text {ads }}\right)$ can be calculated using $N_{\text {ads }}=A_{\text {electrode }} / A_{\text {chl-a }}$, where $A_{\text {electrode }}$ is the electroactive surface area and $A_{\text {chl-a }}$ corresponds to $A_{f l}, A_{e d}$ or $A_{e n}$. However, the electroactive surface area can deviate substantially from the geometric area of electrode and greatly depends on the surface roughness

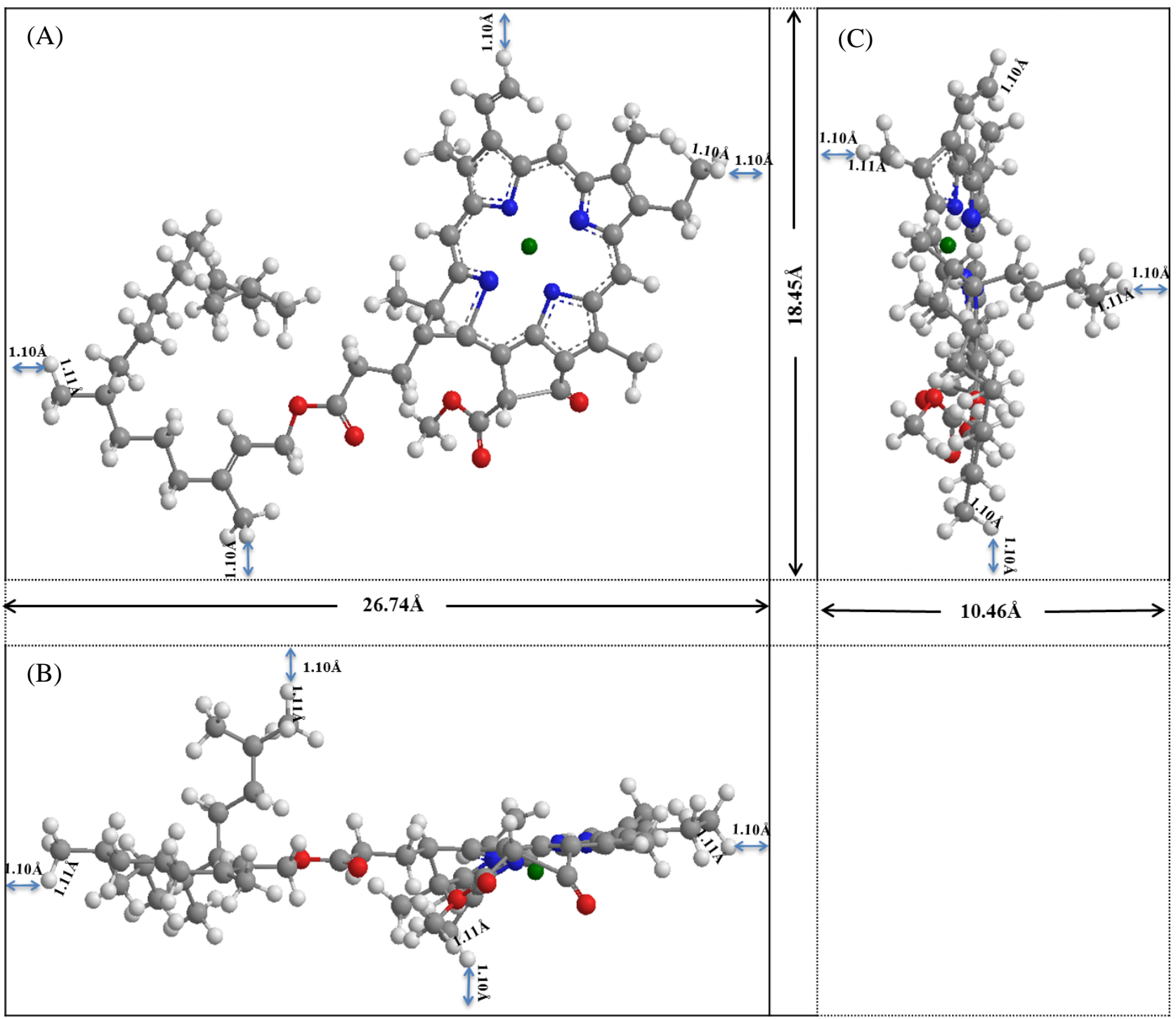

Scheme 1. Rectangular box model of Chl a molecule for (A) flat view, (B) edgewise view and (C) endwise view 
estimated as $0.12-0.29 \mathrm{~cm}^{2}$ and the maximum charge transfer $Q_{\max }$ for three possible molecular orientations can be calculated using $N_{a d s}$ and electron fundamental charge $e\left(1.602 \times 10^{-19} \mathrm{C}\right)$ by $Q_{\max }=N_{a d s} \times e$. Assuming close-packed, monolayer adsorption and a two electron transfer process, the maximum charge transfer for three molecular orientations $Q_{f l}, Q_{e d}$ and $Q_{e n}$ were calculated to lay in the ranges of $0.78-1.9 \mu \mathrm{C}$, 1.4-3.3 $\mu \mathrm{C}, 2.0-4.8 \mu \mathrm{C}$, respectively. Since the experimental $Q_{\max }$ values obtained from Figure 2(D) falls into the range of $Q_{e n}$, it can be inferred that the $\mathrm{Chl}$ a adsorption follows the orientation of the endwise views (Scheme 1(C)).

Following the same procedure, voltammetric responses of $\mathrm{Chl} b$ at the same concentration range of 1.45$370 \mu \mathrm{M}$ were shown in Figure 2(E). The double reciprocal plot in Figure 2(F) again shows linearity (1/ $Q$ $\left.\left(\mu \mathrm{C}^{-1}\right)=(5.679 \pm 0.120) 1 / C\left(\mu \mathrm{M}^{-1}\right)+(0.254 \pm 0.0383), \mathrm{R}^{2}=0.998\right)$, as predicted by Langmuir isotherm, giving an equilibrium constant as $0.045 \mu \mathrm{M}^{-1}$ and the maximum charge transfer as $3.9 \mu \mathrm{C}$. The maximum charge transfers of $\mathrm{Chl} \mathrm{b}$ and $\mathrm{Chl}$ a were found to be very close in values. Since they possess closely similar molecular structures and thus similar surface areas, it can be inferred that the adsorption of Chl b on a GC electrode is similar to that suggested above for Chl a.

\subsection{Detection of Chlorophyll a and $b$ in Mixtures}

\subsubsection{Selective Detection in Standard Mixture Solutions}

Semi-circular potential wave with an average scan rate of $100 \mathrm{mVs}^{-1}$ (Figure 3(A)) was employed for the electrochemical identification and quantification of $\mathrm{Chl} a$ and $\mathrm{Chl} \mathrm{b}$ in the two component mixture owing to its capacity for distinguishing two species with similar redox potentials (Y. Uchida et al., 2018b). The GC electrode was prepared with the same procedure as above for $\mathrm{CV}$ and measured in PBS solution $(\mathrm{pH}=7.4)$. The semi-circular potential sweep voltammograms of backgrounds and a 1:1 mixture solution containing 46.2 $\mu \mathrm{M} \mathrm{Chl} \mathrm{a} \mathrm{and} \mathrm{Chl} \mathrm{b}$ at varying potential windows are shown in Figure 3(B). The influence of the adjustment of potential windows by moving the centre of the sweep relative to the potential of maximum current was discussed in previous work (Amin et al., 2019; Wang et al., 2019). By approximating the midpoint of potential window $E_{\text {centre }}\left(E_{\text {mid }}\right)$ to the oxidative potential of the studied compounds, maximum peak currents can be obtained. As depicted in Figure 5, a set of broad peaks can be observed in the presence of a Chl $(\mathrm{a}+\mathrm{b})$ mixture, as well as an additional very sharp peak near $E_{\text {centre, }}$, where the infinite temporary 
scan rate is generated. With the shift of potential windows towards the more positive $E_{\text {centre }}$, both of the broad peaks increase in amplitude, while the second peak grows more rapidly and the resolution of two broad peak in voltammograms improves with increasing peak separations until $E_{\text {centre }}$ reached $+0.405 \mathrm{~V}$, two distinct peaks can be seen at $+0.46 \mathrm{~V}$ and $+0.57 \mathrm{~V}$. From $E_{\text {centre }}=0.410 \mathrm{~V}$, two peaks began to decrease in resolution and finally merged with the sharp peak at $E_{\text {centre }}=+0.500 \mathrm{~V}$. As for the sharp peak, it continually grew with the increase of positive potentials, suggesting the possible contributions from the capacitive current.

The semi-circular potential sweep voltammetric responses of both $\mathrm{Chl}$ a and $\mathrm{Chl} b$ were recorded separately in the potential window of $E_{\text {centre }}=+0.405 \mathrm{~V}$ and compared with the mixture voltammogram (Figure 4(A)). The two peaks present in the mixture voltammogram were found at the similar peak positions in the case of the isolate components, thus they can be identified as successfully recorded $\mathrm{Chl}$ a and $\mathrm{Chl} b$ peaks. The recorded semi-circular voltammograms with a potential window applied at $E_{\text {centre }}=+0.405 \mathrm{~V}$ showed excellent repeatability in the detection of mixtures, giving stable oxidation signals of $\mathrm{Chl}$ a and $\mathrm{Chl} \mathrm{b}$ that can be measured for both singular components and mixtures with peak potential within a few millivolts.

Figure 4(B) compares the conventional cyclic voltammetric responses with the semi-circular voltammetric responses at the same average scan rate $\left(100 \mathrm{mVs}^{-1}\right)$ under the optimised potential window. It can be seen that using the semi-circular potential wave, the peak currents gained significant amplifications in the region near $E_{\text {centre }}$ with the large, transient scan rates changing within the sweep, making the $\mathrm{Chl}$ a and $\mathrm{Chl} \mathrm{b}$ peaks clearly distinguishable within the 1:1 mixture, in stark contrast the cyclic voltammogram shows no clear separation of the peaks due to the closeness of the oxidation potentials of two species. Thus the semi-circular voltammetry was seen to be more advantageous for the selective detection in mixtures. It was used for further quantifications of chlorophyll mixtures at the optimised potential window with $E_{\text {centre }}=+0.405 \mathrm{~V}$, as next discussed. 
(A)

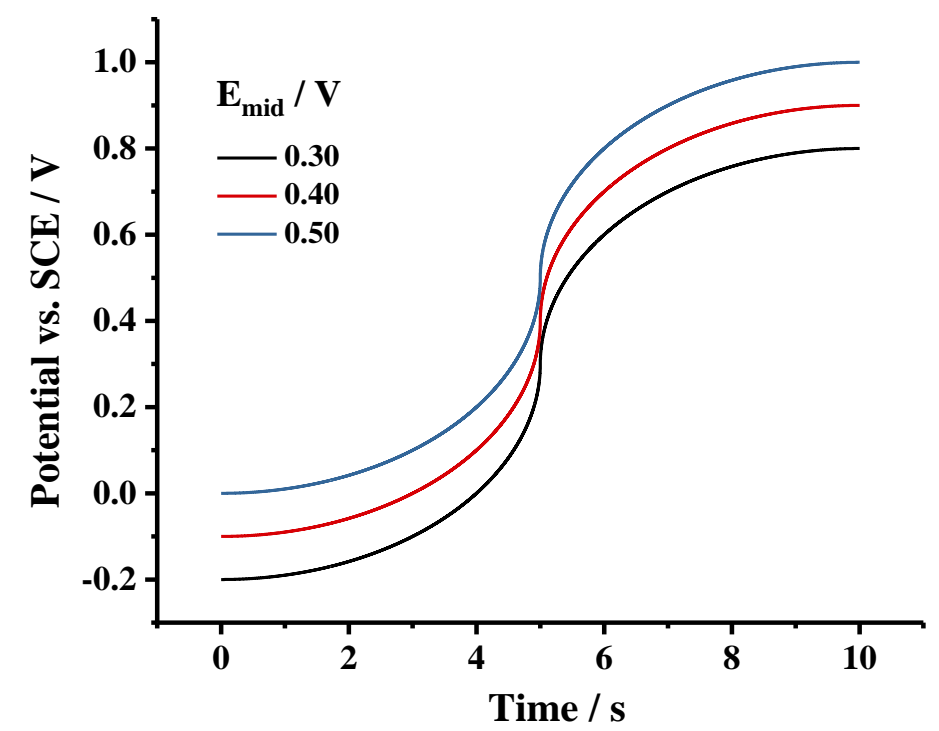

(B)
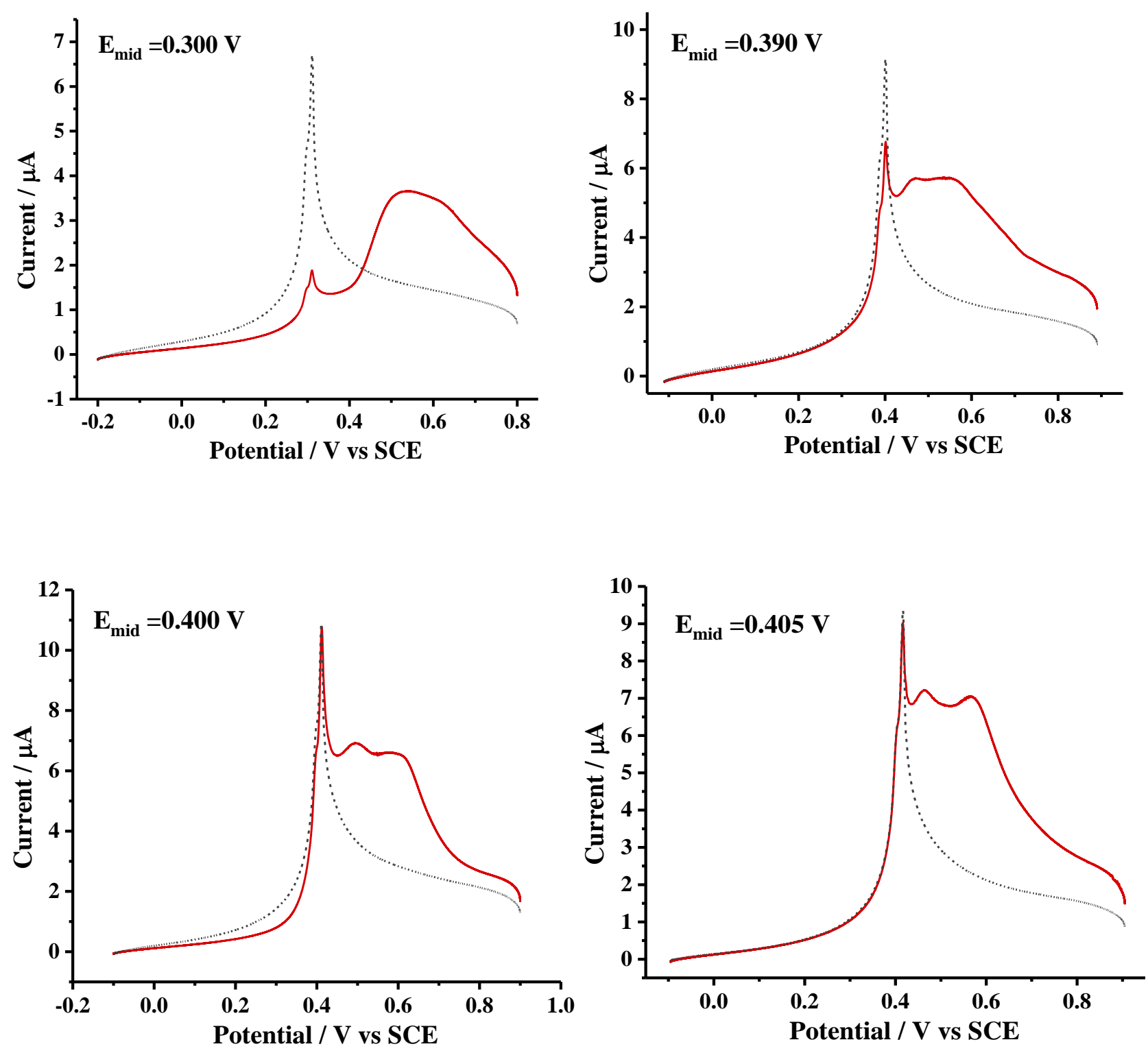

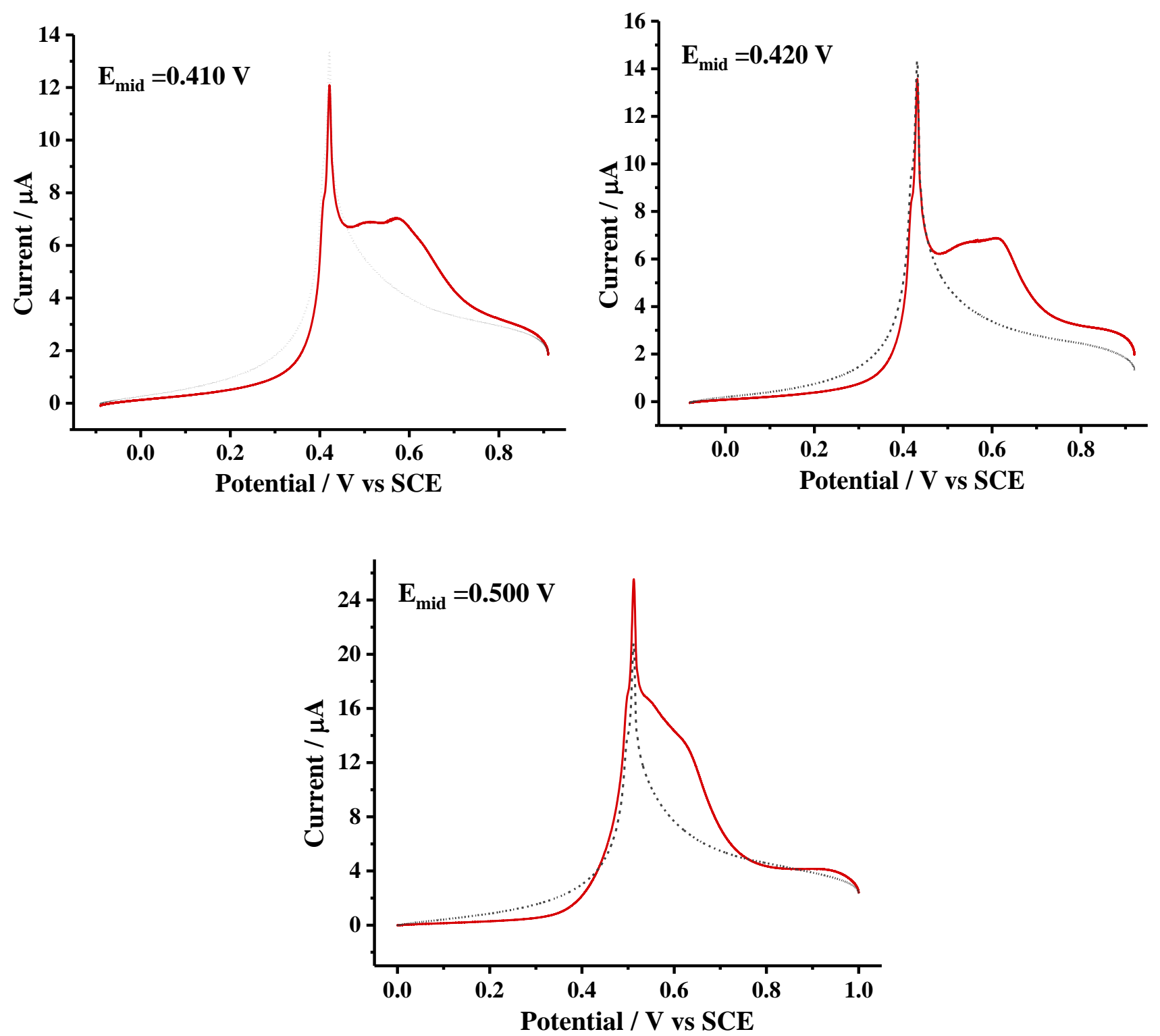

Figure 3. Semi-circular potential sweep voltammetry settings: Semi-circular potential (A) waveforms applieded for varying $\mathrm{E}_{\text {centre. }}$ (B) voltammetric responses of $0 \mu \mathrm{M}$ and $46.2 \mu \mathrm{M}$ of $1: 1 \mathrm{Chl} \mathrm{a:} \mathrm{Chl} \mathrm{b} \mathrm{mixture} \mathrm{solution} \mathrm{at} \mathrm{varying} \mathrm{potential} \mathrm{windows.} \mathrm{The} \mathrm{average} \mathrm{of} \mathrm{scan}$ rate was $100 \mathrm{mVs}^{-1}$. The scan amplitude was $0.5 \mathrm{~V}$. 

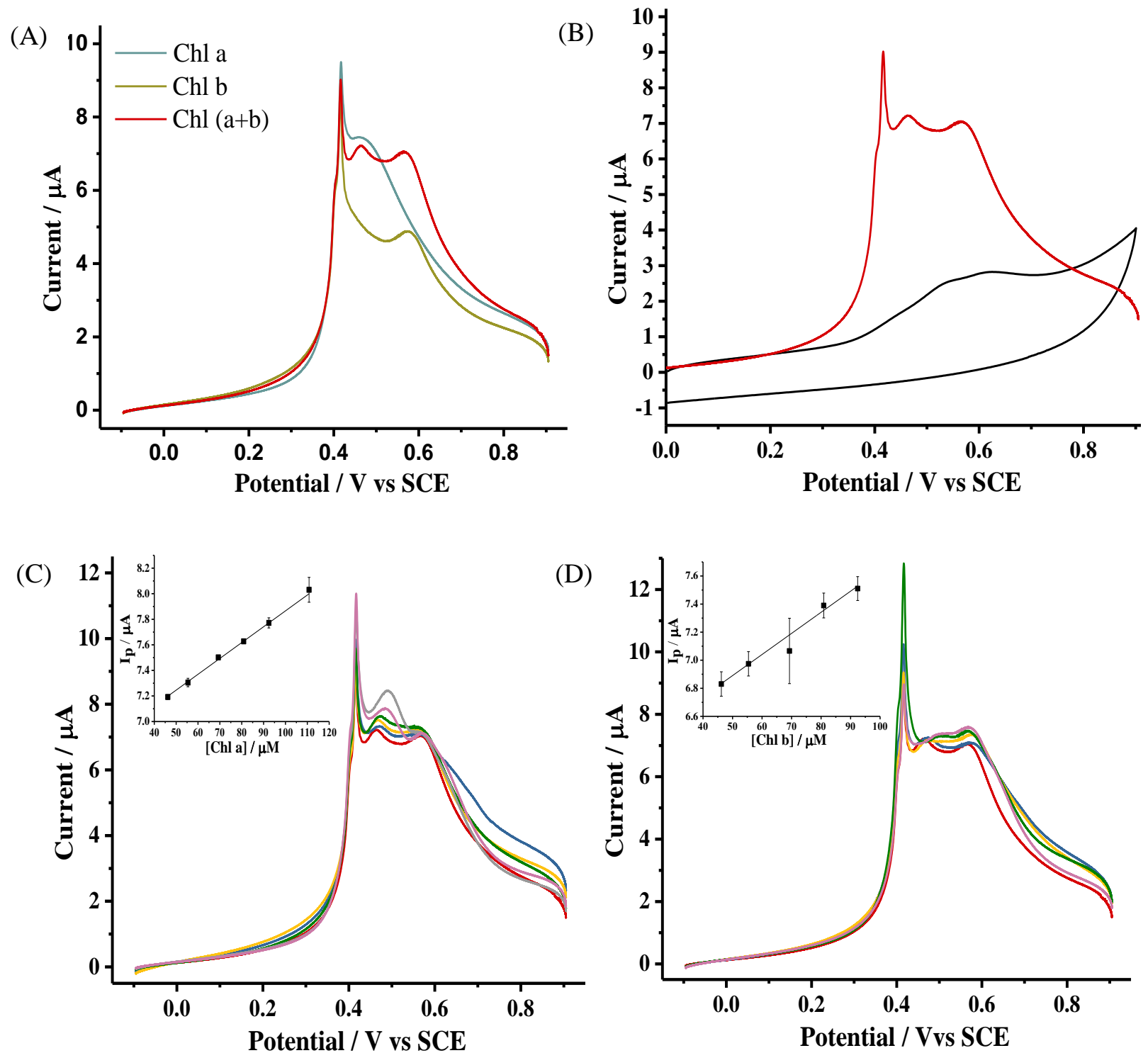

Figure 4. Semi-circular potential sweep voltammetry for the chlorophyll system: Semi-circular potential sweep voltammetric responses at the potential window with $E_{\text {centre }}=+0.405 \mathrm{~V}$ of (A) $46.2 \mu \mathrm{M}$ of $\mathrm{Chl}$ a, Chl b and 1 standard additions of (B) $46.2 \mu \mathrm{M}$ 1:1 Chl a: Chl b mixture in comparison to cyclic voltammogram (black line) of $46.2 \mu \mathrm{M} \mathrm{1:1} \mathrm{Chl} \mathrm{a:} \mathrm{Chl} \mathrm{b} \mathrm{mixture;} \mathrm{standard} \mathrm{additions}$ of (C) $0-64.6 \mu \mathrm{M}$ of $\mathrm{Chl}$ a and (D) $0-46.2 \mu \mathrm{M}$ of Chl b to a $46.2 \mu \mathrm{M} \mathrm{1:1} \mathrm{Chl} \mathrm{a:} \mathrm{Chl} \mathrm{b} \mathrm{mixture} \mathrm{solution.} \mathrm{The} \mathrm{insets} \mathrm{of} \mathrm{(C):} \mathrm{Plot} \mathrm{of}$ currents read at $+0.47 \mathrm{~V}$ increase with $\mathrm{Chl}$ a concentration in the range of $46.2-110.8 \mu \mathrm{M}$; (D): Plot of currents read at $+0.57 \mathrm{~V}$ increase with $\mathrm{Chl} b$ concentration in the range of $46.2-92.4 \mu \mathrm{M}$. The average scan rate was $100 \mathrm{mVs}^{-1}$.

The validated method was applied first for the detection of standard mixture solutions containing varying concentrations of $\mathrm{Chl}$ a and $\mathrm{Chl} \mathrm{b}$. The solutions were prepared by standard addition of $\mathrm{Chl}$ a or $\mathrm{Chl} \mathrm{b}$ solutions to an initial 1:1 mixture containing a total $46.2 \mu \mathrm{M} \mathrm{Chl}(\mathrm{a}+\mathrm{b})$ and adsorbed on the GC electrode using the procedure reported above, the voltammetry was then measured in PBS solution $(\mathrm{pH}=7.4)$. Three scans were conducted for each $\mathrm{Chl}$ a or $\mathrm{Chl} \mathrm{b}$ concentration and the electrode was polished prior to each scan. 
The semi-circular potential sweep voltammetric responses were recorded as a function of the concentrations of Chl a (Figure $4(\mathrm{C})$ ) and $\mathrm{Chl} \mathrm{b}$ (Figure $4(\mathrm{D})$ ). The currents resulting from $\mathrm{Chl}$ a standard addition were measured at a fixed potential of $+0.47 \mathrm{~V}$ and found to exhibit a linear relationship in the concentration range of $46.2-111 \mu \mathrm{M}$ (Figure $4(\mathrm{C})$ inset, $\mathrm{I}_{\mathrm{p}} / \mu \mathrm{A}=\left(1.24 \times 10^{-2} \pm 3.12 \times 10^{-4}\right)[\mathrm{Chl} \mathrm{a}](\mu \mathrm{M})+\left(6.63 \pm 2.43 \times 10^{-2}\right)$ $\left.(\mu \mathrm{A}), \mathrm{N}=6, \mathrm{R}^{2}=0.997\right)$ ). Linear behaviour was also obtained for currents recorded at the fixed potential of $+0.57 \mathrm{~V}$ for the analysis of $\mathrm{Chl} \mathrm{b}$ standard addition. In the range of $46.2-92.4 \mu \mathrm{M}, \mathrm{I}_{\mathrm{p}} / \mu \mathrm{A}=\left(1.50 \times 10^{-2} \pm 8.88\right.$ $\left.\times 10^{-4}\right)[\mathrm{Chl} \mathrm{b}](\mu \mathrm{M})+\left(6.14 \pm 6.33 \times 10^{-2}\right)(\mu \mathrm{A}), \mathrm{N}=5, \mathrm{R}^{2}=0.990$ (Figure $4(\mathrm{D})$ inset). It can be seen that the currents read at the chosen potentials near $\mathrm{Chl}$ a and $\mathrm{Chl} b$ peaks increase linearly with the standard additions of each component. Good reproducibility was obtained between separate experiments and sequential voltammetric measurements (see error bars in Figures 4 and 5), allowing analysis of the mixture and suggesting semi-circular potential sweep voltammetry is a useful analytical technique in selective detection and quantification of individual species within a mixture of them.

\subsubsection{Detection in Real Samples}

In order to access the full applicability of developed method for mixture detection, chlorophyll determination in a real sample was next investigated. As is general for common green plants, the spinach crude product obtained from the mentioned extraction procedure (Section 1 in Supporting Information) without purifying by column chromatography contains several pigment components including carotenoids (carotenes and xanthophylls), chlorophylls ( $\mathrm{Chl} \mathrm{a}$ and $\mathrm{Chl} \mathrm{b)}$ ) and pheophytins (pheophytin a and b). Nonetheless, $\mathrm{Chl}$ a is the most abundant pigment consisting of ca. $58 \%-75 \%$ of the total pigments in spinach (Khachik, Beecher, \& Whittaker, 1986; Kidmose, Edelenbos, Christensen, \& Hegelund, 2005). Therefore, we sought to detect $\mathrm{Chl}$ a content selectively in the mixture of crude extract as a measure for spinach quality control. Cyclic voltammetry and semi-circular voltammetry were first performed for the diluted spinach extract at the average scan rate of $100 \mathrm{mVs}^{-1}$ using the potential window with the optimised $E_{\text {centre }}$ value of +0.405 V. From Figure 5 (A), two main peaks arising from analyte can be observed in semi-circular voltammogram, which merged as one broad peak in cyclic voltammogram, again suggesting that the semicircular voltammetry can provide improved resolution and accuracy in mixture detection. 
To identify the Chl a peak in extract voltammogram and quantify the Chl a contents in spinach, the extract sample was next 'spiked' with Chl a standard solutions. The semi-circular potential sweep voltammetric responses of the spiked solutions with addition of $\mathrm{Chl}$ a in the concentration range of $23.1-80.9 \mu \mathrm{M}$ was depicted in Figure 5 (B). A linear relationship was established between currents read at $+0.49 \mathrm{~V}$ and the concentration of Chl a: $\mathrm{I}_{\mathrm{p}} / \mu \mathrm{A}=\left(2.24 \times 10^{-2} \pm 1.30 \times 10^{-3}\right)[\mathrm{Chl} \mathrm{a}](\mu \mathrm{M})+\left(7.93 \pm 7.12 \times 10^{-2}\right)(\mu \mathrm{A}), \mathrm{N}=6$, $\mathrm{R}^{2}=0.987$ ) (Figure 5 (B) Inset). The Chl a concentration in the spinach extract can be determined as ca. 105 $\mu \mathrm{M}$ from the intercept of Figure 5 (B) inset combined with the linear expression in Inset of Figure 4 (C). This can be converted into the $\mathrm{Chl}$ a content in fresh, raw spinach as ca. $235 \mathrm{mg} / \mathrm{kg}$ and can be estimated as method (Lopez-Ayerra, Murcia, \& Garcia-Carmona, 1998).
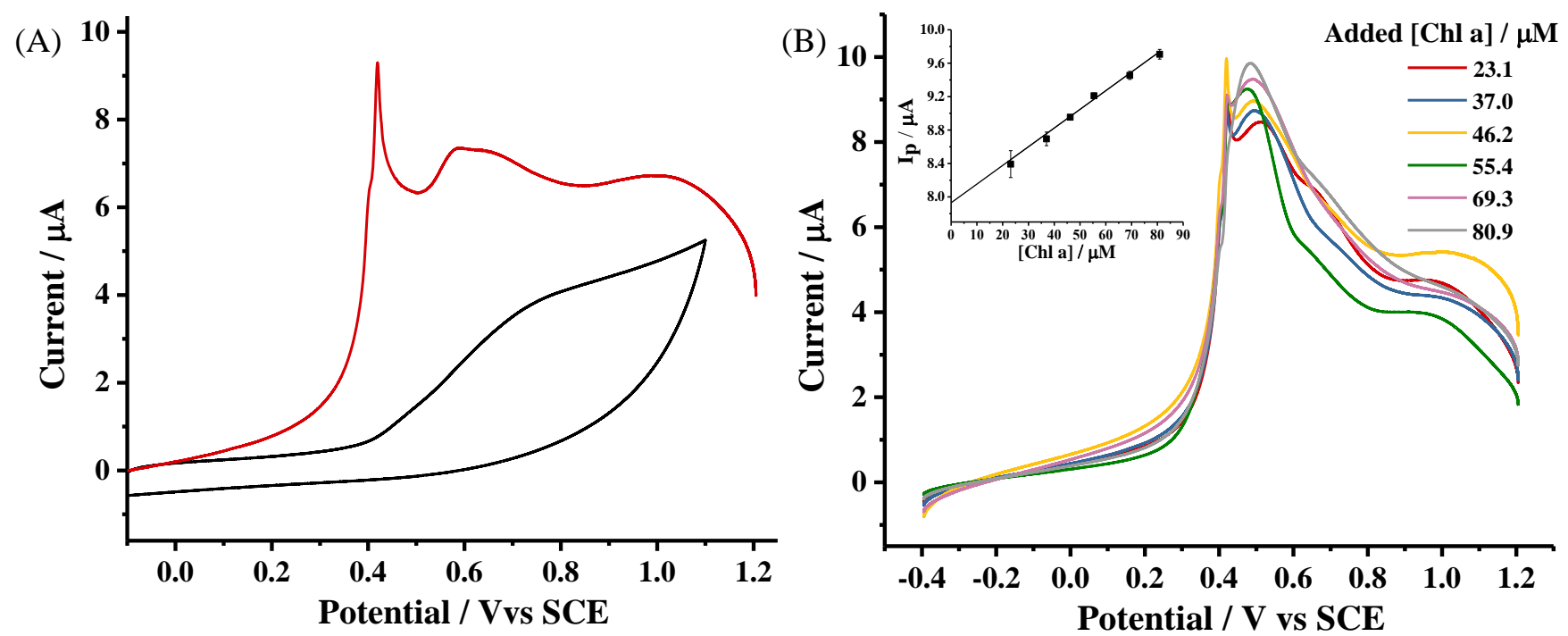

Figure 5. Semi-circular potential sweep voltammetry for the real sample: Semi-circular potential sweep voltammetric responses at the potential window with $E_{\text {centre }}=+0.405 \mathrm{~V}$ of (A) the real sample extracted from spinach in comparison to cyclic voltammogram (black line). (B) standard additions of 23.1-80.9 $\mu \mathrm{M}$ of $\mathrm{Chl}$ a solutions to the real sample extracted from spinach at the potential window with $E_{\text {centre }}=+0.405 \mathrm{~V}$. Inset of (B): Plot of currents read at $+0.49 \mathrm{~V}$ increase with $\mathrm{Chl}$ a concentration in the range of 23.1-80.9 $\mu \mathrm{M}$ The average scan rate was $100 \mathrm{mVs}^{-1}$. 


\section{Conclusions}

We have studied the electrochemical process of two chlorophyll species, Chl a and Chl b on a GC electrode based on their cyclic voltammograms and introduced a novel method for the selective detection of the individual species in the mixtures of them, using the semi-circular potential sweep voltammetry. Conventional cyclic voltammetric study revealed the similarity between the voltammograms of Chl a and $\mathrm{Chl} \mathrm{b}$, in particular, the similar peak potentials, yet failed to distinguish them in a good resolution when they are present in a mixture. The semi-circular potential wave employing the potential window with the optimised $E_{\text {centre }}$ can selectively detect the mixtures of $\mathrm{Chl}$ a and $\mathrm{Chl} \mathrm{b}$ in the concentration range of 46.2-111 $\mu \mathrm{M}$ and 46.2-92.4 $\mu \mathrm{M}$, respectively, complementing the conventional method in electroanalysis. The developed method was also successfully applied for analysing the real sample 'spiked' with Chl a, suggesting the potential use of semi-circular potential sweep voltammetry for the electroanalytical detection of mixtures consisting of more than one electrochemically active species with closely similar peak potentials, as the results of a simpler extraction / purification process suitable for practical use.

\section{Conflict of interests}

The authors declare that they have no conflict of interest.

\section{Reference}

Agostiano, A., Cosma, P., \& Dellamonica, M. (1990). Spectroscopic and Electrochemical Characterization of Chlorophyll-a in Different Water + Organic-Solvent Mixtures. Bioelectrochemistry and Bioenergetics, 23(3), 311-324.

Amin, H. M. A., Uchida, Y., Katelhon, E., \& Compton, R. G. (2019). Semi-circular potential sweep voltammetry: Experimental verification and determination of the formal potential of a reversible redox couple. Journal of Electroanalytical Chemistry, 836, 62-67. doi:10.1016/j.jelechem.2019.01.058

Bard, A. J., Faulkner, L. R., Zoski, C. G., \& Leddy, J. (2001). Electrochemical methods : fundamentals and applications (Second edition. ed.). New York: Wiley.

Batsanov, S. S. (2001). Van der Waals radii of elements. Inorganic Materials, 37(9), 871-885.

Boyer, J. N., Kelble, C. R., Ortner, P. B., \& Rudnick, D. T. (2009). Phytoplankton bloom status: Chlorophyll a biomass as an indicator of water quality condition in the southern estuaries of Florida, USA. Ecological Indicators, 9, S56-S67. doi:10.1016/j.ecolind.2008.11.013

Cecchi, T., Passamonti, P., \& Cecchi, P. (2010). Study of the quality of extra virgin olive oil stored in PET bottles with or without an oxygen scavenger. Food Chem, 120(3), 730-735. doi:10.1016/j.foodchem.2009.11.001

Chen, L., Li, X., Tanner, E. E. L., \& Compton, R. G. (2017). Catechol adsorption on graphene nanoplatelets: isotherm, flat to vertical phase transition and desorption kinetics. Chemical Science, 8(7), 4771-4778.

Chen, L., Tanner, E. E. L., Lin, C., \& Compton, R. G. (2018). Impact electrochemistry reveals that graphene nanoplatelets catalyse the oxidation of dopamine via adsorption. Chemical Science, 9(1), 152-159. 
Choe, E., \& Min, D. B. (2006). Mechanisms and Factors for Edible Oil Oxidation. Comprehensive Reviews in Food Science and Food Safety, 5(4), 169-186. doi:10.1111/j.1541-4337.2006.00009.x

Compton, R. G., \& Banks, C. E. (2018). Understanding voltammetry (Third Edition ed.). London: World Scientific Publishing Europe.

Conte, L., Milani, A., Calligaris, S., Rovellini, P., Lucci, P., \& Nicoli, M. C. (2020). Temperature Dependence of Oxidation Kinetics of Extra Virgin Olive Oil (EVOO) and Shelf-Life Prediction. Foods, 9(3). doi:10.3390/foods9030295.

Engineering ToolBox, E. (2003). Water Content in Food and other Products. https://www.engineeringtoolbox.com/water-content-d 131.html

Ergun, E., Demirata, B., Gumus, G., \& Apak, R. (2004). Simultaneous determination of chlorophyll a and chlorophyll b by derivative spectrophotometry. Analytical and Bioanalytical Chemistry, 379(5-6), 803-811. doi:10.1007/s00216-004-2637-7

Falk, J. E., \& Smith, K. M. (1975). Porphyrins and metalloporphyrins (New ed.). Amsterdam ; Oxford: Elsevier.

Goedheer, J. C., Dehaas, G. H. H., \& Schuller, P. (1958). Oxidation-Reduction Potentials of Different Chlorophylls in Methanol. Biochimica Et Biophysica Acta, 28(2), 278-283. doi:10.1016/00063002(58)90474-8

Iriyama, K., \& Shiraki, M. (1979). Improved Method for Extraction, Partial-Purification, Separation and Isolation of Chlorophyll from Spinach Leaves. Journal of Liquid Chromatography, 2(2), 255-276.

Isleroglu, H., Sakin-Yilmazer, M., Kemerli-Kalbaran, T., Uren, A., \& Kaymak-Ertekin, F. (2017). Kinetics of colour, chlorophyll, and ascorbic acid content in spinach baked in different types of oven. International Journal of Food Properties, 20(11), 2456-2465.

Khachik, F., Beecher, G. R., \& Whittaker, N. F. (1986). Separation, Identification, and Quantification of the Major Carotenoid and Chlorophyll Constituents in Extracts of Several Green Vegetables by LiquidChromatography. Journal of Agricultural and Food Chemistry, 34(4), 603-616.

Khanova, L. A., \& Tarasevich, M. R. (1987). Electrochemistry and Photoelectrochemistry of Chlorophyll on a Metallic Electrode .1. Properties of Chlorophyll Adsorption Films on Metals. Journal of Electroanalytical Chemistry, 227(1-2), 99-114. doi: 10.1016/0022-0728(87)80068-2

Kidmose, U., Edelenbos, M., Christensen, L. P., \& Hegelund, E. (2005). Chromatographic determination of changes in pigments in spinach (Spinacia oleracea L.) during processing. Journal of Chromatographic Science, 43(9), 466-472.

Kobayashi, M., Ohashi, S., Iwamoto, K., Shiraiwa, Y., Kato, Y., \& Watanabe, T. (2007). Redox potential of chlorophyll d in vitro. Biochimica Et Biophysica Acta-Bioenergetics, 1767(6), 596-602.

Lopez-Ayerra, B., Murcia, M. A., \& Garcia-Carmona, F. (1998). Lipid peroxidation and chlorophyll levels in spinach during refrigerated storage and after industrial processing. Food Chem, 61(1-2), 113-118. doi:10.1016/S0308-8146(97)00099-X

Maxwell, K., \& Johnson, G. N. (2000). Chlorophyll fluorescence - a practical guide. Journal of Experimental Botany, 51(345), 659-668. doi: 10.1093/jexbot/51.345.659

Murray, R. W. (1992). Molecular design of electrode surfaces. New York: Wiley.

Nonomura, Y., Igarashi, S., Yoshioka, N., \& Inoue, H. (1997). Spectroscopic properties of chlorophylls and their derivatives. Influence of molecular structure on the electronic state. Chemical Physics, 220(1-2), 155-166.

Pemberton, R. M., Amine, A., \& Hart, J. P. (2004). Voltammetric behavior of chlorophyll a at a screenprinted carbon electrode and its potential role as a biomarker for monitoring fecal contamination. Analytical Letters, 37(8), 1625-1643. doi:10.1081/Al-120037592

Scheer, H. (1991). Chlorophylls. Boca Raton, Fla.: CRC Press.

Schoefs, B. (2003). Chlorophyll and carotenoid analysis in food products. A practical case-by-case view. Trac-Trends in Analytical Chemistry, 22(6), 335-339. doi:10.1016/S0165-9936(03)00602-2

Silva, S. F., Anjos, C. A. R., Cavalcanti, R. N., \& Celeghini, R. M. D. (2015). Evaluation of extra virgin olive oil stability by artificial neural network. Food Chem, 179, 35-43. doi: 10.1016/j.foodchem.2015.01.100

Suponeva, E. P., Hotchandani, S., Arbour, C., \& Kisselev, B. A. (1996). Electrochemical oxidation of microcrystalline chlorophyll a. Biologicheskie Membrany, 13(3), 229-235.

Suponeva, E. P., Kazakova, A. A., \& Kisselev, B. A. (1989). Electrochemical Oxidation of Chlorophyll-a in Thin-Films at Pt and Sno2 Electrodes. Bioelectrochemistry and Bioenergetics, 22(1), 75-81.

Trypidis, D., Garcia-Gonzalez, D. L., Lobo-Prieto, A., Nenadis, N., Tsimidou, M. Z., \& Tena, N. (2019). Real time monitoring of the combined effect of chlorophyll content and light filtering packaging on 
virgin olive oil photo-stability using mesh cell-FTIR spectroscopy. Food Chem, 295, 94-100. doi: 10.1016/j.foodchem.2019.05.084

Uchida, Y., Kätelhön, E., \& Compton, R. (2019). Stripping voltammetry with semi-circular potential waves: reversible systems. Journal of Electroanalytical Chemistry, 848, 113290.

Uchida, Y., Katelhon, E., \& Compton, R. G. (2018a). Linear sweep voltammetry with non-triangular waveforms at a microdisc electrode. Journal of Electroanalytical Chemistry, 823, 465-473. doi:10.1016/j.jelechem.2018.06.049

Uchida, Y., Katelhon, E., \& Compton, R. G. (2018b). Linear sweep voltammetry with non-triangular waveforms: New opportunities in electroanalysis. Journal of Electroanalytical Chemistry, 818, 140148. doi:10.1016/j.jelechem.2018.04.028

Uchida, Y., Katelhon, E., \& Compton, R. G. (2019). Sweep voltammetry with a semi-circular potential waveform: Electrode kinetics. Journal of Electroanalytical Chemistry, 835, 60-66. doi:10.1016/j.jelechem.2018.12.030

Vernon, L. P., \& Seely, G. R. (1966). The chlorophylls. New York ; London: Academic Press.

Wang, Y., Chen, L., Chaisiwamongkhol, K., \& Compton, R. G. (2019). Electrochemical quantification of piperine in black pepper. Food Chem, 309, 125606. doi:10.1016/j.foodchem.2019.125606

Yang, Y. G., Zhou, R. L., Han, Y. Y., \& Jiang, Y. S. (1994). Electrochemical Study of Chlorophyll-a Adsorbed on Sno2. Journal of Electroanalytical Chemistry, 370(1-2), 269-271.

Zhang, J., Han, W., Huang, L., Zhang, Z., Ma, Y., \& Hu, Y. (2016). Leaf Chlorophyll Content Estimation of Winter Wheat Based on Visible and Near-Infrared Sensors. Sensors (Basel), 16(4), 437. doi: $10.3390 / \mathrm{s} 16040437$ 